\title{
ANALISIS KESESUAIAN LAHAN DI KAWASAN HUTAN DENGAN TUJUAN KHUSUS (KHDTK) BULUH CINA, RIAU
}

\section{Analysis of Land in Forest Area with Special Purposes (KHDTK) Buluh Cina, Riau}

\author{
Hanifah Ikhsani' ${ }^{1}$ Azwin ${ }^{2}$, Muhammad Ikhwan ${ }^{3}$ \\ ${ }^{1,2,3)}$ Staff Pengajar Fakultas Kehutanan Universitas Lancang Kuning \\ Jln. Yos Sudarso Km. 8 Rumbai Pekanbaru Riau \\ Email:hanifah@unilak.ac.id ${ }^{1}$,azwin@unilak.ac.id ${ }^{2}$, mmighwan@unilak.ac.id ${ }^{3}$
}

Diterima: 19 Juni 2021, Direvisi: 21 Juni 2021, Disetujui: 14 Juli 2021

DOI: 10.31849/forestra.v16i2.7077

\begin{abstract}
Forest Area with Special Purposes (KHDTK) Buluh Cina requires a land suitability analysis so that the development of plant species can be carried out optimally. This study aims to map land units and determine land suitability classes. This study uses aerial photography to classify land cover and take soil samples. Furthermore, overlay analysis and species matching were carried out for 7 types of plants including durian, rambutan, sengon, mango, cacao, pineapple, and corn. The land suitability class is divided into 4 levels namely, very suitable (S1), suitable (S2), marginally suitable (S3), and not suitable (N). Based on the results, the actual land suitability class at KHDTK Buluh Cina class S1 was rambutan at SPL I and III. Land suitability class S2 is rambutan at SPL II and IV. S3 land suitability classes are durian, sengon, mango, cocoa, pineapple, and corn in SPL I, II, III, and IV. The potential land suitability class at KHDTK Buluh Cina class S1 is rambutan at SPL I, II, III and IV. Land suitability class S2 is durian, sengon, and cocoa at SPL I, II, III, and IV. S3 land suitability class is mango, pineapple, and corn in SPL I, II, III, and IV.
\end{abstract}

Keywords : Land Suitability, KHDTK Buluh Cina, Species Matching

\section{ABSTRAK}

Kawasan Hutan Dengan Tujuan Khusus (KHDTK) hutan pendidikan Buluh Cina memerlukan adanya analisis kesesuaian lahan di KHDTK Buluh Cina agar pengembangan jenis tanaman dapat dilakukan secara optimal. Penelitian ini bertujuan untuk memetakan satuan lahan dan menentukan kelas kesesuaian lahan. Penelitian ini menggunakan foto udara untuk mengklasifikasikan tutupan lahan dan mengambil sampel tanah. Selanjutnya dilakukan analisis overlay dan species matching 7 jenis tanaman diantaranya durian, rambutan, sengon, mangga, coklat, nenas dan jagung. Kelas kesesuaian lahan terbagi menjadi 4 tingkat yaitu sangat sesuai (S1), sesuai (S2), sesuai marjinal (S3), dan tidak sesuai $(\mathrm{N})$. Berdasarkan hasil penelitian, kelas kesesuaian lahan aktual di KHDTK Buluh Cina kelas S1 adalah tanaman rambutan pada SPL I dan III. Kelas kesesuaian lahan S2 adalah tanaman rambutan pada SPL II dan IV. Kelas kesesuaian lahan S3 adalah tumbuhan durian, sengon, mangga, coklat, nenas dan jagung pada SPL I, II, III dan IV. Kelas kesesuaian lahan potensial di KHDTK 
Buluh Cina kelas S1 adalah tanaman rambutan pada SPL I, II, III dan IV. Kelas kesesuaian lahan S2 adalah tanaman durian, sengon dan coklat pada SPL I, II, III dan IV. Kelas kesesuaian lahan S3 adalah tumbuhan mangga, nenas dan jagung pada SPL I, II, III dan IV.

Kata kunci : Kesesuaian Lahan, Kesesuaian Jenis, KHDTK Buluh Cina

\section{PENDAHULUAN}

Lahan merupakan suatu lingkungan fisik yang terdiri atas iklim, topografi, tanah, hidrologi, dan vegetasi dimana pada batas-batas tertentu mempengaruhi kemampuan penggunaan lahan (Rayes 2007). Setiap lahan memiliki karakteristik dan keterbatasan yang akan menentukan kapabilitas atau kemampuannya, sehingga diperlukan suatu tindakan khusus yang berbeda-beda untuk setiap jenis tanah dalam pengembangannya.

Pengembangan jenis tanaman yang tidak didasarkan pada analisis kesesuaian lahan akan menyebabkan produksi yang tidak optimal (Butarbutar et al., 2018; Rahim, Hasnain \& Shamsi, 2010). Salah satu pengembangan tersebut bisa dilakukan dengan sistem agroforestri. Optimalisasi produktivitas agroforestri di berbagai wilayah telah dilakukan melalui pemilihan jenis pohon, antara lain tanaman berkayu, tanaman serbaguna atau Multy Purpose Tree Species (MPTs), tanaman perkebunan, tanaman pertanian (pangan), dan tanaman pakan ternak berdasarkan analisis kesesuaian lahan (Asmarhansyah et al., 2017; Butarbutar et al., 2018). Penilaian kesesuaian lahan untuk pengembangan agroforestri ditunjukkan untuk mengetahui kesediaan zat hara, keadaan topografi, altitude dan karakteristik lahan lainnya di lokasi yang dikembangkan (Ahmad et al., 2017).

Evaluasi lahan merupakan salah satu komponen penting dalam proses perencanaan penggunaan lahan (land use planning). Salah satu bentuk evaluasi lahan adalah klasifikasi kemampuan lahan. Hasil klasifikasi lahan dapat digunakan untuk menentukan arahan penggunaan lahan secara umum misalnya untuk budidaya tanaman semusim, perkebunan, hutan produksi, dan sebagainya. Saat ini KHDTK Buluh Cina ditanami kelapa sawit oleh masyarakat sekitar secara ilegal, sehingga perlu upaya menganalisis kesesuaian lahan untuk melihat jenis-jenis tumbuhan tahunan dan semusim apa saja yang memungkinkan untuk dibudidayakan di lokasi KHDTK 
dalam praktek agroforestri yang ingin dikembangkan.

KHDTK Buluh cina merupakan Kawasan Hutan Dengan Tujuan Khusus (KHDTK) hutan pendidikan Buluh Cina. KHDTK ini merupakan bagian dari Taman Wisata Alam Bulu Cina, yang berlokasi di kecamatan Siak Hulu, kabupaten Kampar dengan luas \pm 103 Ha. Penelitian di lokasi ini masih sangat terbatas, terutama keterbatasan informasi mengenai jenis yang sesuai di KHDTK Buluh cina. Oleh karena itu, penelitian ini penting untuk dilakukan.

Tujuan penelitian ini adalah untuk memetakan satuan lahan dan menentukan kelas kesesuaian lahan di KHDTK Buluh Cina, Riau.

\section{METODE PENELITIAN}

\subsection{Waktu dan Tempat}

Penelitian dilaksanakan pada bulan Oktober sampai dengan April 2021. Tempat penelitian adalah KHDTK Buluh Cina, Kabupaten Kampar Provinsi Riau. Lokasi penelitian dapat dilihat pada Gambar 1. Analisis data tanah dilakukan di Laboratorium Tanah, Fakultas Pertanian Universitas Riau, sedangkan pengolahan dan analisis data drone dilakukan di Laboratorium Perencanaan dan Manajemen Hutan Fakultas Kehutanan Universitas Lancang Kuning.

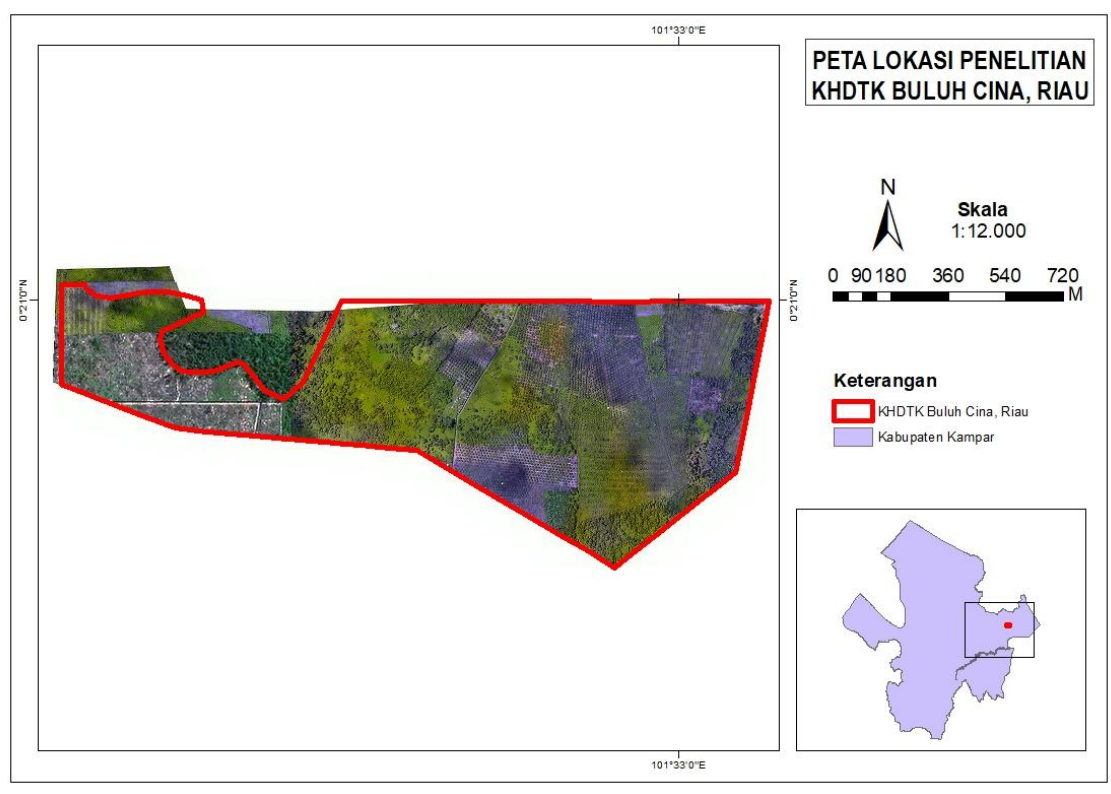

Gambar 1. Peta Lokasi Penelitian 


\subsection{Alat dan Data}

Alat yang digunakan berupa alat pengambilan data dan analisis data. Alat pengambilan data lapangan berupa GPS, kompas, bor gambut, ring sampel tanah, cangkul, kamera, smartphone yang dilengkapi dengan aplikasi Dji Go 4 dan Pix4dCapture, UAV jenis Dji Phantom 4, tally sheet, dan alat tulis. Alat dan software analisis data yang digunakan berupa ArcGIS version 10.8, Quantum GIS version 2.14.6, Agisoft Photoscan, Microsoft Word, dan Microsoft Excel.

Data primer yang digunakan pada penelitian ini terdiri atas foto udara yang diambil langsung di lapangan menggunakan wahana UAV dan sampel tanah, sedangkan data sekunder terdiri atas peta batas wilayah administrasi KHDTK Buluh Cina Riau, peta penutupan lahan Provinsi Riau, peta kemiringan lahan (kelerengan) KHDTK Buluh Cina, data suhu dan curah hujan di Kabupaten Kampar bulan Januari sampai dengan April 2021.

\subsection{Prosedur Penelitian}

\section{Persiapan Penelitian}

Pada tahapan ini dilakukan pembuatan perencanaan jalur terbang
UAV untuk penerbangan UAV jenis $D j i$ Phantom 4 di KHDTK Buluh Cina, Riau. Penentuan batas yang akan menjadi jalur terbang UAV didasarkan pada keberagaman kelas tutupan lahan yang didapat dari data sekunder. Setiap 1 kelas penutupan lahan yang ada di KHDTK Buluh Cina kemudian diambil sampel minimal 1 titik pengamatan lapang dan 1 titik blok terbang UAV yang dapat mewakili adanya perbedaan tutupan lahan.

Selanjutnya, dilakukan juga persiapan alat dan data sekunder lainnya yang dibutuhkan pada penelitian ini.

\section{Tahapan Penelitian di Lapangan}

Tahapan ini merupakan pengumpulan data primer yang meliputi parameter fisik yang dapat diukur di lapangan, yaitu pengambilan foto udara menggunakan drone dan pengambilan sampel tanah.

Pengambilan sampel tanah untuk dianalisis di laboratorium berupa keasaman tanah dan c-organik. Sifat-sifat lahan (land characteristic) adalah atribut atau keadaan unsur-unsur lahan yang dapat diukur atau diperkirakan seperti tekstur tanah, curah hujan, temperatur dan drainase tanah. Sifat 
lahan ini menentukan perilaku lahan yang mempengaruhi pertumbuhan tanaman (Arsyad, 2006). Sifat-sifat lahan (land characteristic) disajikan pada Tabel 1.

Berdasarkan penampakan dari orthophoto, jenis tutupan lahan di KHDTK ini hanya ada 2 jenis, yaitu tutupan semak belukar dan tutupan perkebunan sawit. Tutupan lahan yang relatif homogen in karena hanya ada 2 klasifikasi tutupan lahan sehingga metode pengambilan sampel dengan purposive sampling. Sampel tanah diambil secara acak pada 6 titik pengamatan berdasarkan peta tanah Kabupaten Kampar yang mewakili gambaran sifat tanah di lokasi tersebut. Agar contoh representatif maka contoh tanah dari suatu strata diambil dengan metode zig-zag dimana setiap titik diambil contoh kira-kira 1-2 kg dengan bantuan bor tanah pada kedalaman 0-20 cm (Mukhlis, 2007). Selanjutnya untuk menetukan permeabilitas dan sifat kimia tanah dilakukan dengan Analisis tanah di Laboratorium.

\section{Analisis Klasifikasi Kesesuaian Lahan}

Tahapan ini dilakukan dengan metode matching atau pencocokan data yang telah diperoleh baik dari data primer, sekunder, maupun data hasil laboratorium dengan persyaratan penggunaan lahan.

Klasifikasi kesesuaian lahan dilaksanakan dengan cara memadukan antara kebutuhan tanaman atau persyaratan tumbuh tanaman dengan karakteristik lahan. Adapun jenis tanaman yang akan dipadukan adalah tanaman tahunan dan musiman. Oleh karena itu klasifikasi ini sering juga disebut species matching.

Proses evaluasi lahan dilakukan dengan cara mencocokkan (matching) antara karateristik lahan pada setiap lokasi dengan persyaratan tumbuh tanaman. Jenis tanaman tahunan yang dievaluasi yaitu durian (Durio zibethinus), rambutan (Nephelium lappaceum), sengon (Paraserianthes falcataria), mangga (Mangifera indica L.), coklat (Theobroma cacao L.), nenas (Ananas comosus) dan jagung (Zea mays). Pemilihan jenis tanaman yang direkomendasikan berdasarkan jenis tanaman yang banyak ditemukan di Kabupaten Kampar, Riau.

Kesesuaian lahan adalah kecocokan suatu lahan untuk penggunaan tertentu, seperti pada penelitian ini yaitu lahan sesuai untuk agroforestri tanaman tahunan dan tanaman semusim. Kelas kesesuaian 
lahan terbagi menjadi empat tingkat yaitu sangat sesuai (S1), sesuai (S2), sesuai marjinal (S3), dan tidak sesuai $(\mathrm{N})$.

Hasil akhir dari klasifikasi ditetapkan berdasarkan kelas terburuk dengan memberikan seluruh pembatas/hambatan yang ada. Perubahan klasifikasi menjadi setingkat lebih baik dimungkinkan terjadi apabila seluruh hambatan yang ada dapat diperbaiki. Sub klas pada klasifikasi kesesuaian lahan ini juga mencerminkan jenis penghambat. Ada tujuh jenis penghambat yang dikenal, yaitue (erosi), w (drainase), s (tekstur tanah), a (keasaman), g (kelerengan), sd (kedalaman tanah) dan c (iklim) (Azis et al., 2006).

Klasifikasi kesesuaian lahan dilakukan dengan melalui sortasi data karakteristik lahan berdasarkan kriteria kesesuaian lahan untuk setiap jenis tanaman. Hubungan antara karakteristik kesesuaian lahan dan tingkat pembatas dapat dilihat pada Tabel 2 (Azis et al., 2006).

Tabel 1. Variabel yang digunakan dalam kriteria evaluasi lahan

\begin{tabular}{lll}
\hline Simbol & \multicolumn{1}{c}{ Kualitas lahan } & \multicolumn{1}{c}{ Karakteristik lahan } \\
\hline $\mathrm{Tc}$ & Temperatur & Temperatur \\
$\mathrm{Wa}$ & Ketersediaan air & Curah hujan $(\mathrm{mm})$ \\
$\mathrm{Rc}$ & Media perakaran & Tekstur \\
& & Permeabilitas tanah \\
$\mathrm{Nr}$ & Retensi hara & $\mathrm{pH}$ \\
$\mathrm{Eh}$ & Bahaya erosi & C-organik $(\%)$ \\
\hline
\end{tabular}

Tabel 2. Hubungan antara karakteristik kesesuaian lahan dan tingkat pembatas

\begin{tabular}{ll}
\hline \multicolumn{1}{c}{ Tingkat pembatas } & Karakteristik kesesuaian lahan \\
\hline $0:$ no (tidak ada) & $\mathrm{S} 1:$ sangat sesuai \\
1 : Slight (ringan) & $\mathrm{S} 2$ : cukup sesuai \\
$2:$ Moderate (sedang) & $\mathrm{S} 3:$ sesuai marginal \\
$3:$ Severe (berat) & $\mathrm{N}:$ tidak sesuai \\
$4:$ Very severe (sangat berat) &
\end{tabular}




\section{HASIL DAN PEMBAHASAN}

\section{Peta Satuan Lahan di KHDTK Buluh} Cina

Berdasarkan hasil penggabungan atau overlay peta penggunaan lahan, peta lereng, peta kontur dan peta tanah, ditemukan 4 unit lahan dengan luasan yang berbeda-beda. Perbandingan luas unit lahan di KHDTK Buluh Cina dapat dilihat pada Tabel 3.
Unit lahan yang terluas adalah unit lahan I dengan luas 57,919 ha $(55,92 \%)$ dan luas unit lahan terkecil adalah unit lahan II dengan 1,887 ha $(1,82 \%)$. Peta unit lahan lokasi penelitian dapat dilihat pada Gambar 2.

Tabel 3. Luas masing-masing satuan unit lahan di KHDTK Buluh Cina

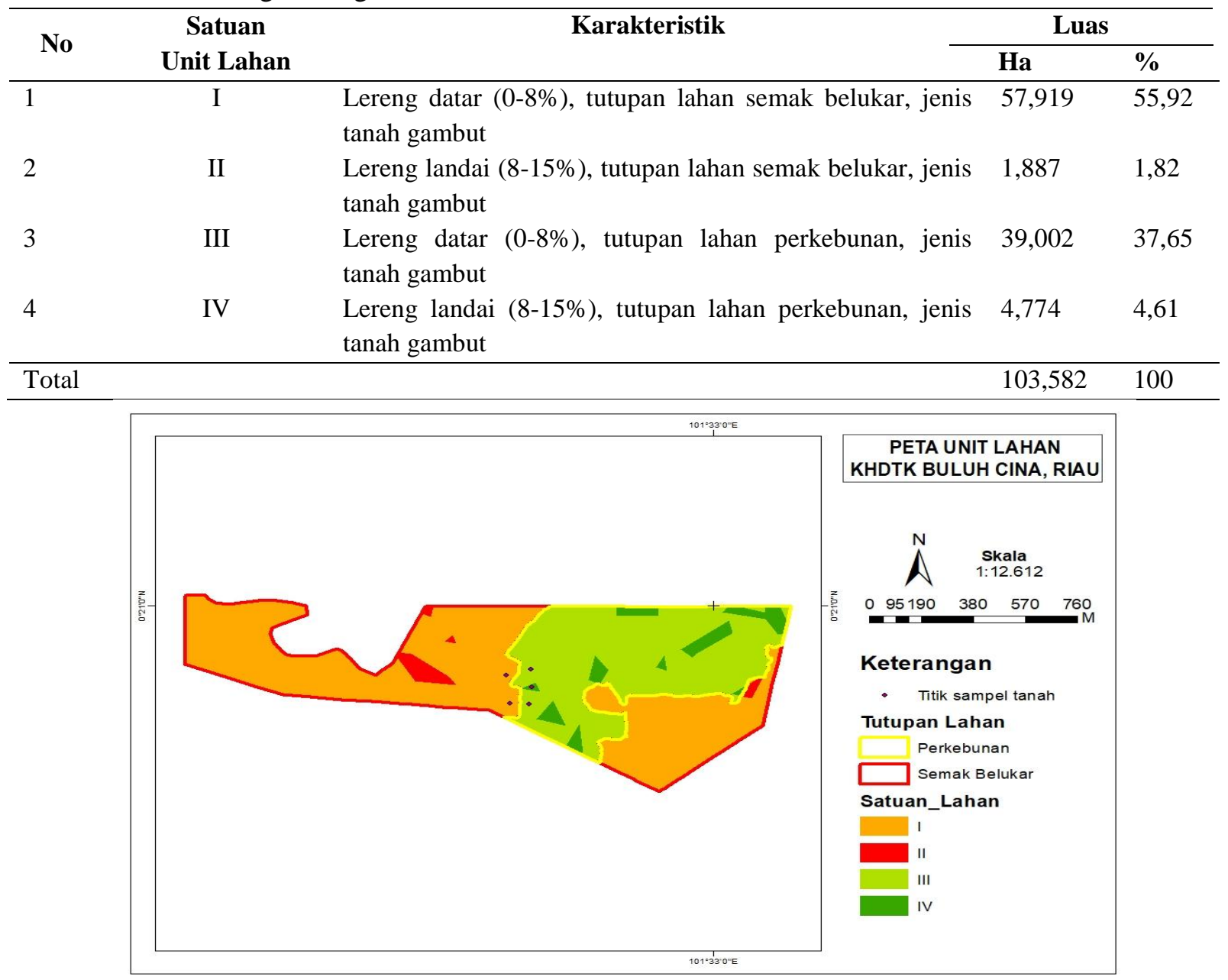

Gambar 2. Peta satuan lahan di KHDTK Buluh Cina 


\section{Kesesuaian Lahan di KHDTK Buluh Cina}

Hasil pengumpulan data sekunder, data primer dan hasil analisis tanah di laboratoriummaka karakteristik lahan dapat ditampilkan pada sebuah tabel.
Karakteristik unit lahan tersebut disajikan pada Tabel 4. Jenis tanaman tersebut dianalisis lebih lanjut sehingga dihasilkan kesesuaian lahan pada setiap jenis tanaman (Tabel 5).

Tabel 4. Karakteristik unit lahan di KHDTK Buluh Cina

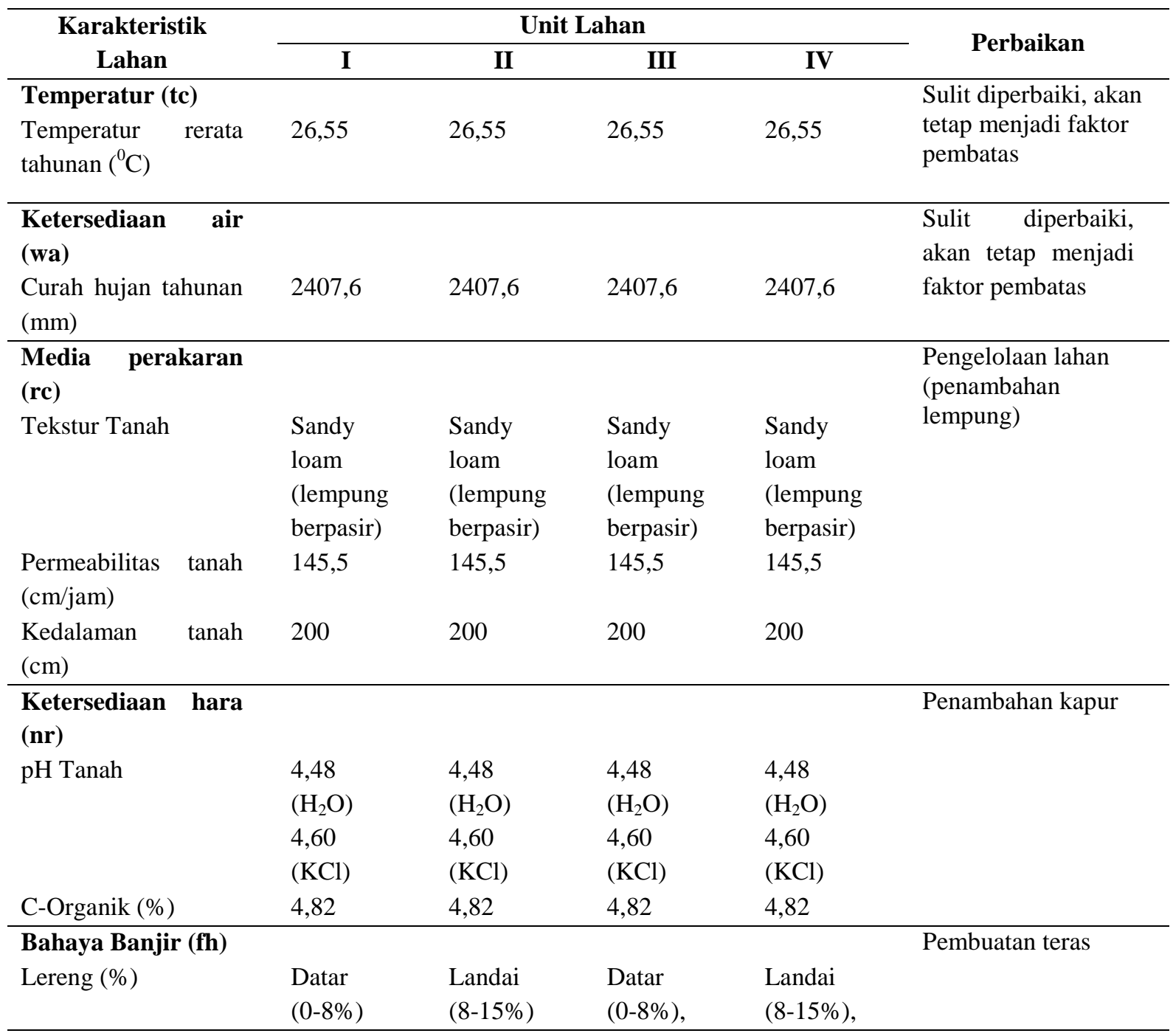


Tabel 5. Kesesuaian Lahan Jenis Tanaman

\begin{tabular}{|c|c|c|c|c|c|}
\hline \multirow{2}{*}{ Jenis Tanaman } & \multirow{2}{*}{$\begin{array}{c}\text { Kelas Kesesuaian } \\
\text { Lahan }\end{array}$} & \multicolumn{4}{|c|}{ Unit Lahan } \\
\hline & & I & II & III & IV \\
\hline \multirow{2}{*}{ Durian (Durio zibethinus) } & Aktual & S3nr & S3nr, fh & S3nr & S3nr, fh \\
\hline & Potensial & S2nr & $\mathrm{S} 2 \mathrm{nr}$,fh & $\mathrm{S} 2 \mathrm{nr}$ & S2nr, fh \\
\hline \multirow{2}{*}{$\begin{array}{ll}\text { Rambutan } & \text { (Nephelium } \\
\text { lappaceum) }\end{array}$} & Aktual & S1 & $\mathrm{S} 2 \mathrm{fh}$ & S1 & S2fh \\
\hline & Potensial & S1 & S1fh & S1 & S1fh \\
\hline \multirow{2}{*}{$\begin{array}{l}\text { Sengon (Paraserianthes } \\
\text { falcataria) }\end{array}$} & Aktual & S3rc, nr & S3rc, nr, fh & S3rc, nr & S3rc, nr, fh \\
\hline & Potensial & $\mathrm{S} 2 \mathrm{rc}, \mathrm{nr}$ & S2rc, nr, fh & S2rc, nr & S2rc, nr, fh \\
\hline \multirow[t]{2}{*}{$\begin{array}{l}\text { Mangga (Mangifera indica } \\
\text { L.) }\end{array}$} & Aktual & $\begin{array}{l}\text { S3wa, rc, } \\
\text { nr }\end{array}$ & $\begin{array}{l}\text { S3wa, rc, } \\
\text { nr, fh }\end{array}$ & $\begin{array}{l}\text { S3wa, rc, } \\
\text { nr }\end{array}$ & $\begin{array}{l}\text { S3wa, re, } \\
\text { nr, fh }\end{array}$ \\
\hline & Potensial & S3wa & S3wa & S3wa & S3wa \\
\hline \multirow{2}{*}{$\begin{array}{l}\text { Coklat (Theobroma cacao } \\
\text { L.). }\end{array}$} & Aktual & S3nr & S3nr, fh & S3nr & S3 nr, fh \\
\hline & Potensial & S2 & $\mathrm{S} 2$ & $\mathrm{~S} 2$ & $\mathrm{~S} 2$ \\
\hline \multirow[t]{2}{*}{ Nenas (Ananas comosus) } & Aktual & $\begin{array}{l}\text { S3tc, wa, } \\
\text { nr }\end{array}$ & $\begin{array}{l}\text { S3tc, wa, } \\
\text { nr, fh }\end{array}$ & $\begin{array}{l}\text { S3tc, wa, } \\
\text { nr }\end{array}$ & $\begin{array}{l}\text { S3tc, wa, } \\
\text { nr, fh }\end{array}$ \\
\hline & Potensial & S3tc wa & S3tc wa & S3tc, wa & S3tc wa \\
\hline \multirow[t]{2}{*}{ Jagung (Zea mays) } & Aktual & S3tc, nr & S3tc, nr, fh & S3tc, nr & S3tc, nr, fh \\
\hline & Potensial & S3tc & S3tc & S3tc & S3tc \\
\hline
\end{tabular}

Keterangan :

Tc : Temperatur

Wa : Ketersediaan air

rc : Media Perakaran

$\mathrm{nr} \quad$ : Ketersediaan hara

fh : Bahaya banjir

\section{Kesesuaian Lahan Jenis Tanaman}

\section{A. Durian}

Berdasarkan hasil pencocokan karakteristik tanah dengan tanaman durian (Tabel 5) pada Satuan Peta Lahan (SPL) I dan III, maka diperoleh kelas kesesuaian lahan aktual adalah sesuai marginal (S3) dengan faktor pembatas bahaya ketersediaan hara yaitu $\mathrm{pH}$ tanah (nr). Diasumsikan bahwa lahan ini termasuk ke dalam lahan gambut tergradasi. Kesesuaian lahan terhadap pertumbuhan tanaman menurun pada lahan gambut yang terdegradasi. Gambut terdegradasi memiliki ciri antara lain: menurunnya kemampuan memegang air (hidrofobik) akibat sifat gambut yang irreversible drying serta meningkatnya kemasaman tanah (Anshari, 2010). Degradasi lahan gambut dapat disebabkan oleh pengelolaan lahan yang tidak tepat antara lain pembukaan lahan, pembuatan saluran drainase, kebakaran atau pembakaran lahan gambut.

Faktor pembatas tersebut dapat diperbaiki dengan pengapuran. Kondisi rendahnya $\mathrm{pH}$ tanah tersebut dapat 
diperbaiki dengan pengapuran sehingga akan diperoleh kelas kesesuaian lahan potensial adalah cukup sesuai /S2. Rayes (2007); Das \& Sudhakar, (2014) menyatakan bahwa untuk karakteristik lahan retensi hara dengan faktor $\mathrm{pH}$ tanah dapat diperbaiki dengan usaha pengapuran. Selain itu, hal yang dapat dilakukan adalah pemberian amelioran. Amelioran atau disebut dengan pembenah tanah merupakan bahan yang ditambahkan ke dalam tanah untuk memperbaiki lingkungan akar bagi pertumbuhan tanaman. Pemberian amelioran dimaksudkan sebagai sumber hara, mengurangi kemasaman tanah dan sebagai sumber pengikat atau penjerap kation-kation yang tercuci ke daerah lain akibat pengaturan tata air dan efektif untuk pertumbuhan tanaman (Maas et al., 2013).

Pada hasil pencocokan karakteristik tanah dengan tanaman durian pada SPL II dan IV, maka diperoleh kelas kesesuaian lahan aktual adalah sesuai marginal / S3 dengan faktor pembatas bahaya ketersediaan hara yaitu $\mathrm{pH}$ tanah (nr) dan bahaya banjir (fh) yaitu kelerengan. Untuk faktor pembatas lereng dapat diperbaiki dengan pembuatan teras dan penanaman sejajar kontur sehingga akan diperoleh kelas kesesuaian lahan potensial adalah cukup sesuai /S2. Satriawan et al., (2015); Permana et al., (2017); Pasaribu et al. (2018) menerangkan bahwa faktor penghambat bahaya erosi dapat diatasi dengan pembuatan teras, penanaman sejajar kontur, dan penanaman penutup tanah. Begitu juga dengan Hartati et al. (2018) menyatakan bahwa usaha pengurangan laju erosi memang dapat dilakukan dengan pembuatan teras, penanaman sejajar kontur maupun penanaman tanaman penutup tanah, namun dengan kelerengan yang lebih dari $30 \%$ upaya tindakan pengelolaan untuk mengatasi faktor pembatas pada lahan ini tentu membutuhkan biaya yang cukup tinggi.

\section{B. Rambutan}

Berdasarkan hasil pencocokan karakteristik tanah dengan tanaman rambutan (Tabel 5) pada SPL I dan III, maka diperoleh kelas kesesuaian lahan aktual adalah sangat sesuai / S1 tanpa faktor pembatas. Lahan ini tidak mempunyai pembatas yang berat untuk suatu penggunaan secara lestari atau hanya mempunyai pembatas yang tidak berarti dan tidak berpengaruh secara nyata 
terhadap produksinya.

SPL II dan IV, maka diperoleh kelas kesesuaian lahan aktual adalah cukup sesuai / S1 dengan faktor pembatas bahaya lereng. Faktor pembatas dapat diperbaiki sehingga akan diperoleh kelas kesesuaian lahan potensial adalah sangat sesuai /S1.

\section{Sengon}

Berdasarkan hasil pencocokan karakteristik tanah dengan tanaman sengon (Tabel 5) pada SPL I dan III, maka diperoleh kelas kesesuaian lahan aktual adalah sesuai marginal/ S3 dengan faktor pembatas bahaya media perakaran berupa tekstur tanah dan keterbatasan hara berupa $\mathrm{pH}$ tanah. Serupa dengan satuan penggunaan lahan sebelumnya dengan karakteristik faktor pembatas yang serupa, maka dengan perbaikan faktor pembatas yang ada akan diperoleh kelas kesesuaian lahan potensial adalah cukup sesuai /S2.

Pada SPL II dan IV, maka diperoleh kelas kesesuaian lahan aktual adalah cukup sesuai / S2 dengan faktor pembatas bahaya media perakaran berupa tekstur tanah, keterbatasan hara berupa $\mathrm{pH}$ tanah dan bahaya banjir berupa lereng. Tekstur tanah merupakan salah satu faktor yang mempengaruhi kapasitas tanah untuk menahan air. Tanah yang bertekstur halus mempunyai infiltrasi yang cukup tinggi akan tetapi jika terjadi aliran permukaan maka butir-butir halus akan terangkut bersamaan (Yunagardasari et al., 2017). Matus et al., (2008) menyatakan bahwa tekstur tanah adalah faktor utama yang mempengaruhi kandungan Karbon (C) dan Nitrogen (N) di dalam tanah. Adanya perbaikan dari seluruh faktor pembatas akan membuat kelas kesesuaian lahan potensial menjadi cukup sesuai /S2.

\section{Mangga}

Berdasarkan hasil pencocokan karakteristik tanah dengan tanaman mangga (Tabel 5) pada SPL I dan III, maka diperoleh kelas kesesuaian lahan aktual adalah sesuai marginal/ S3 dengan faktor pembatas bahaya curah hujan, media perakaran berupa tekstur tanah dan keterbatasan hara berupa $\mathrm{pH}$ tanah. Faktor curah hujan merupakan faktor alam yang tidak dapat diperbaiki sehingga akan tetap menjadi faktor pembatas dalam kesesuaian lahan pada SPL ini. Faktor pembatas alami tersebut tidak dapat diperbaiki sehingga kelas kesesuaian lahan potensial adalah 
tetap sesuai marginal /S3. Begitu juga untuk SPL II dan IV, karena ada faktor pembatas alami yaitu curah hujan yang tidak dapat dirubah maka kelas kesesuaian lahan potensial adalah sesuai marginal /S3.

\section{E. Coklat}

Berdasarkan hasil pencocokan karakteristik tanah dengan tanaman coklat (Tabel 5) pada Satuan Peta Lahan (SPL) I dan III, maka diperoleh kelas kesesuaian lahan aktual adalah sesuai marginal / S3 dengan faktor pembatas bahaya ketersediaan hara yaitu $\mathrm{pH}$ tanah (nr). Faktor pembatas tersebut dapat diperbaiki agar diperoleh kelas kesesuaian lahan potensial cukup sesuai/ S2.

Pada hasil pencocokan karakteristik tanah dengan tanaman coklat pada SPL II dan IV, maka diperoleh kelas kesesuaian lahan aktual adalah tidak sesuai marginal / S3 dengan faktor pembatas bahaya ketersediaan hara yaitu $\mathrm{pH}$ tanah (nr) dan bahaya banjir (fh) yaitu kelerengan. Faktor pembatas tersebut dapat diperbaiki agar diperoleh kelas kesesuaian lahan potensial cukup sesuai/ S2.

\section{F. Nenas}

Pada SPL I dan III, diperoleh kelas kesesuaian lahan aktual tanaman nenas adalah sesuai marginal / S3 dengan faktor pembatas bahaya temperatur yaitu suhu, ketersediaan air yaitu curah hujan dan ketersediaan hara yaitu $\mathrm{pH}$ tanah (nr). Faktor pembatas bahaya suhu dan curah hujan merupakan faktor alam sehingga tidak dapat dirubah, sehingga kelas kesesesuaian lahan potensial adalah sesuai marginal /S3.

Pada hasil pencocokan karakteristik tanah dengan tanaman nenas pada SPL II dan IV, maka diperoleh kelas kesesuaian lahan aktual adalah tidak sesuai marginal/ S3 dengan faktor pembatas bahaya temperatur yaitu suhu (tc), ketersediaan air yaitu curah hujan (wa), ketersediaan hara yaitu $\mathrm{pH}$ tanah (nr) dan bahaya banjir adalah lereng (fh). Sama halnya dengan SPL I dan III, faktor pembatas bahaya suhu dan curah hujan yang tidak dapat dirubah, sehingga kelas kesesesuaian lahan potensial adalah sesuai marginal /S3.

\section{G. Jagung}

Berdasarkan hasil pencocokan karakteristik tanah dengan tanaman jagung (Tabel 5) pada SPL I dan III, maka diperoleh kelas kesesuaian lahan aktual 
adalah sesuai marginal / S3 dengan faktor pembatas bahaya temperatur (tc) yaitu suhu dan ketersediaan hara (nr) yaitu $\mathrm{pH}$ tanah. Faktor pembatas suhu yang tidak dapat diperbaiki membuat kelas kesesuaian lahan potensial adalah tetap pada sesuai marginal /S3.

Pada hasil pencocokan karakteristik tanah dengan tanaman jagung pada SPL II dan IV, maka diperoleh kelas kesesuaian lahan aktual adalah cukup sesuai marginal / S2 dengan faktor pembatas bahaya temperatur (tc) yaitu suhu, ketersediaan hara yaitu $\mathrm{pH}$ tanah (nr) dan bahaya banjir (fh) yaitu lereng. Faktor pembatas suhu yang tidak dapat diperbaiki juga membuat kelas kesesuaian lahan potensial adalah tetap pada sesuai marginal /S3.

\section{KESIMPULAN DAN SARAN}

\section{A. Kesimpulan}

Berdasarkan hasil penelitian dan uraian pembahasan dapat diambil kesimpulan sebagai berikut:

1. Kelas kesesuaian lahan aktual yang termasuk ke dalam kelas S1 (sangat sesuai) adalah tanaman rambutan pada SPL I dan III. Kelas kesesuaian lahan S2 (cukup sesuai) adalah tanaman rambutan pada SPL II dan IV. Kelas kesesuaian lahan S3 (sesuai marginal) adalah tumbuhan durian, sengon, mangga, coklat, nenas dan jagung pada SPL I, II, III dan IV.

2. Kelas kesesuaian lahan potensial yang termasuk ke dalam kelas S1 (sangat sesuai) adalah tanaman rambutan pada SPL I, II, III dan IV. Kelas kesesuaian lahan S2 (cukup sesuai) adalah tanaman durian, sengon dan coklat pada SPL I, II, III dan IV. Kelas kesesuaian lahan S3 (sesuai marginal) adalah tumbuhan mangga, nenas dan jagung pada SPL I, II, III dan IV.

3. Tanaman rambutan (Nephelium llapaceum) merupakan tanaman yang sesuai untuk dibudidayakan pada daerah penelitian karena termasuk kedalam kelas kesesuaian lahan sangat sesuai (S1), khususnya pada SPL I dan III.

\section{B. Saran}

Diperlukan analisis dan uji lebih lanjut mengenai setiap karakteristik lahan dan desain tapak pengolahan lahan untuk model perencanaan pengelolaan KHDTK Buluh Cina. 


\section{UCAPAN TERIMA KASIH \\ (ACKNOWLEDGEMENT)}

Terima kasih kepada Fakultas Kehutanan Universitas Lancang Kuning yang telah membiayai penelitian ini.

\section{DAFTAR PUSTAKA}

Ahmad, F., Goparaju, L., \& Qayum, A. (2017). Agroforestry suitability analysis based upon nutrient availability mapping: A GIS based suitability mapping. AIMS Agriculture and Food, 2(2), 201-220. https://doi.org/10.3934/agrfood.2017.2 .201

Asmarhansyah, A., B Badayos, R., B Sanchez, P., C Sta Cruz, P., \& M Florece, L. (2017). Land suitability evaluation of abandoned tin-mining areas for agricultural development in Bangka Island, Indonesia. Journal of Degraded and Mining Lands Management, 04(04), 907-918. https://doi.org/10.15243/jdmlm.2017.0 44.907

Azis, A., Sunarminto, B., \& Renanti, M. (2006). Evaluasi Kesesuaian Lahan Untuk Budidaya Tanaman Pangan Menggunakan Jaringan Syaraf Tiruan. Bimipa, 16(1), 1-10.

Butarbutar, T., Hakim, I., Sakuntaladewi, N., Dwiprabowo, H., Rumboko, L., \& Irawati, S. (2018). Analisis Kesesuaian Lahan Sembilan Jenis Tanaman Untuk Agroforestri Di Nambo, Jawa Barat. Jurnal Penelitian Hutan Tanaman, 15(1), $17-28$. https://doi.org/10.20886/jpht.2018.15. 1.17-28
Das, P. T., \& Sudhakar, S. (2014). Land Suitability Analysis for Orange \&amp; Pineapple: A Multi Criteria Decision Making Approach Using Geo Spatial Technology. Journal of Geographic Information System, 06(01), 40-44. https://doi.org/10.4236/jgis.2014.6100 5

Maas, A., Syukur, A., Penelitian, B., Lahan, P., Pertanian, F., \& Mada, U. G. (2013). Efektivitas Amelioran pada Lahan Gambut Terdegradasi untuk Meningkatkan Pertumbuhan dan Serapan NPK Tanaman Jagung Manis (Zea mays L. var. saccharata). Jurnal Agronomi Indonesia (Indonesian Journal of Agronomy), 41(1), 16-23. https://doi.org/10.24831/jai.v41i1.707 1

Matus, F. J., Lusk, C. H., \& Maire, C. R. (2008). Effects of soil texture, carbon input rates, and litter quality on free organic matter and nitrogen mineralization in Chilean rain forest and agricultural soils. Communications in Soil Science and Plant Analysis, 39(1-2), 187-201. https://doi.org/10.1080/001036207017 59137

Permana, Y. I., Puji, K., \& Yudo, S. T. (2017). Pengaruh Arah Guludan Terhadap Intercroping Tanaman Apel ( Malus sylvestris L .) Pada Pertumbuhan Berbagai Tanaman Hortikultura. Produksi Tanaman, 5(1), 15-23.

Rayes, L . M 2007. Metode Inventarisas. Edisi Kedua. USU Press, Medan.

Satriawan, H., Harahap, E. M., Rahmawaty, \& Karim, A. (2015). Effectiveness of Soil Conservation to Erosion Control on Several Land Use Types. Agriculture, 61(2), 61-68. https://doi.org/10.1515/agri-2015-0011 
Yunagardasari, C., Paloloang, A. K., \& Monde, A. (2017). Model infiltrasi pada berbagai penggunaan lahan di Desa Tulo Kecamatan Dolo Kabupaten Sigi. Agrotekbis, 5(3), 315-323. https://media.neliti.com/media/publica tions/245559-model-infiltrasi-padaberbagai-penggunaa-e9b71eac.pdf 